\title{
DESAFIOS PARA A COORDENAÇÃO INTERGOVERNAMENTAL DO PROGRAMA BOLSA FAMÍLIA
}

\author{
CHALLENGES FOR THE INTERGOVERNMENTAL COORDINATION OF THE BOLSA FAMÍLIA \\ PROGRAM
}

RETOS PARA LA COORDINACIÓN INTERGUBERNAMENTAL DEL PROGRAMA BOLSA FAMÍLIA

\section{RESUMO}

O artigo aborda a coordenação intergovernamental do Programa Bolsa Família (PBF), dado seu objetivo de enfrentamento da pobreza em um país de profunda desigualdade social e regional. Busca qualificar o debate sobre a centralização dos programas de transferência de renda no Brasil por meio da análise das relações intergovernamentais adotadas no âmbito das três principais dimensões do PBF - transferência de renda, acompanhamento de condicionalidades e articulação de programas complementares - considerando-se as implicações federativas derivadas da perspec- tiva intersetorial que rege o Programa. Duas ordens de desafios são destacadas. A primeira relaciona-se à necessidade de maior investimento em espaços e oportunidades de negociação intergovernamental, sobretudo na dimensão da transferência de renda, a qual inicialmente se caracterizou pela centralização. Na segunda, a questão intergovernamental demanda a organização de uma estratégia nacional coordenada de articulação de programas complementares, sugerindo-se maior participação dos estados na coordenação regional do Programa.

PALAVRAS-CHAVE Federalismo, relações intergovernamentais, coordenação intergovernamental, transferência de renda, Bolsa Família.

Elaine Cristina Licio elaine.licio@gmail.com

Doutoranda em Política Social pelo Departamento de Serviço Social, Universidade de Brasília, e Membro da carreira federal de Especialista em Política Pública e Gestão Governamental, Secretaria Nacional de Renda de Cidadania, Ministério do Desenvolvimento Social e Combate à Fome, Brasília - DF, Brasil

Camile Sahb Mesquita camilemesquita@yahoo.com.br

Mestre em Política Social pelo Departamento de Serviço Social, Universidade de Brasília; Membro da carreira federal de Especialista em Política Pública e Gestão Governamental, Secretaria de Gestão, Ministério do Planejamento, Orçamento e Gestão, Brasília - DF, Brasil, e Coordenadora Executiva da Coordenação de Acompanhamento das Políticas Sociais da Casa Civil do Estado da Bahia, Salvador - BA, Brasil

Claudia Regina Baddini Curralero cbaddini@yahoo.com.br

Doutoranda em Economia pelo Instituto de Economia, Universidade de Campinas - Campinas - SP, Brasil e Membro da carreira federal de Especialista em Política Pública e Gestão Governamental, Secretaria de Gestão, Ministério do Planejamento, Orçamento e Gestão, Brasília - DF, Brasil

\begin{abstract}
The paper examines the intergovernmental coordination of the Bolsa Família Program (PBF), given its goal to tackle poverty in a country with deep social and regional inequality. It seeks to qualify the debate on the centralization of cash transfer programs in Brazil through the analysis of intergovernmental relations adopted under the three main dimensions of the PBF - cash transfer, monitoring of conditionalities and articulation of complementary programs - considering the federative implications derived from the intersectoral perspective that drives the Program. Two categories of challenges are highlighted. The first one relates to the need for greater investment in space and opportunities for intergovernmental negotiation, especially in the dimension of income transfer, which initially was characterized by centralization. In the second, the intergovernmental matter demands the organization of a coordinated national strategy for the articulation of complementary programs, suggesting greater involvement of states in the regional coordination of the Program.

Keywords Federalism, intergovernmental relations, intergovernmental coordination, cash transfer, Bolsa Família.

Resumen El artículo examina la coordinación intergubernamental del Programa Bolsa Familia (PBF), teniendo en cuenta su objetivo de luchar contra la pobreza en un país con profundas desigualdades sociales y regionales. Se trata de calificar el debate sobre la centralización de los programas de transferencia de renta en el Brasil por medio de análisis de las relaciones intergubernamentales adoptadas en el ámbito de las tres principales dimensiones del PBF - transferencia de renta, acompañamiento de condicionalidades y articulación de programas complementarios - considerándose las implicaciones federativas derivadas de la perspectiva intersectorial que rige el Programa. Dos órdenes de retos son destacadas. La primera se relaciona a la necesidad de mayor inversión en espacios y oportunidades de negociación intergubernamental, sobre todo en la dimensión de la transferencia de renta, a la cual en principio se caracterizó por la centralización. En la segunda, la cuestión intergubernamental demanda la organización de una estrategia nacional coordinada de articulación de programas complementarios, lo que sugiere una mayor participación de los estados en la coordinación regional del Programa.

Palabras clave Federalismo, relaciones intergubernamentales, coordinación intergubernamental, transferencia de renta, Bolsa Familia.
\end{abstract}




\section{INTRODUÇÃO}

Esse artigo insere-se na temática do federalismo, relações intergovernamentais e políticas públicas tratada pela Ciência Política, cujo principal enfoque consiste nos diferentes movimentos de descentralização e centralização que teriam ocorrido no Brasil nos últimos anos (ALMEIDA, 2001). Busca identificar os principais desafios de coordenação intergovernamental do PBF, o qual atua por meio de transferência condicionada de renda e atende a 12,9 milhões de famílias (48 milhões de pessoas) com rendimento mensal de até R\$ 140,00 per capita com um orçamento inferior a 0,5\% do PIB brasileiro (BRASIL, 2010a). Sua implementação tem mostrado muitas especificidades e evidenciado a emergência de diversas inovações no campo das políticas públicas. Nesse aspecto, ressalta-se o modelo de gestão do Programa, que depende fundamentalmente de uma forte coordenação federativa e intersetorial.

A Constituição Federal (CF) dispõe, no art. 23, $\mathrm{X}$, que é competência comum aos entes federativos "combater as causas da pobreza e os fatores de marginalização, promovendo a integração social dos setores desfavorecidos". Todavia, a CF não avança no estabelecimento de procedimentos e instrumentos necessários para o aprofundamento de uma atuação conjunta, deixando para as políticas públicas o desafio da construção de espaços e oportunidades de negociação permanente entre as esferas de governo.

Segundo a literatura especializada, as políticas de caráter redistributivo, como é o caso do PBF, devem ser nacionais (PETERSON, 1995; BROWN e OATES, 1987). Além disso, visto implicarem uma relação direta do governo federal com os beneficiários, os programas de transferência de renda tenderiam a possuir um desenho federativo centralizado. Diversos autores apontam traços de centralização na implementação dos programas federais de transferência de renda no Brasil (ABRUCIO, 2005; ALMEIDA, 2005; AFONSO, 2006). Todavia, tais análises foram realizadas com base nas primeiras experiências federais dessa natureza e avaliaram os programas como um todo, e não segundo suas dimensões.

Ponderamos que a diversidade das ações dentro de um mesmo programa pode comportar mais de um tipo de arranjo federativo no contínuo centralização-descentralização, implicando relações intergovernamentais mais hierárquicas ou negociadas conforme o caso (WRIGHT, 1988). A principal contribuição desse artigo vem no sentido de aprofundar o debate baseado na análise da dinâmica federativa da gestão do PBF em cada uma das suas três principais dimensões - transferência de renda, acompanhamento de condicionalidades e articulação de programas complementares - levando-se em conta não apenas as relações entre os diversos níveis de governo mas também as implicações federativas derivadas da perspectiva intersetorial que rege o Programa.

Com base nessas premissas, o artigo faz uma reflexão teórica sobre coordenação intergovernamental em sistemas federativos. Após uma breve consideração sobre o contexto político-institucional que caracterizou o desenvolvimento dos programas de transferência condicionada de renda no Brasil, descrevem-se o modelo de gestão do PBF e os diferentes padrões de relações intergovernamentais empreendidos na implementação das suas três dimensões. Por fim, identificam-se os principais desafios de coordenação intergovernamental que hoje se colocam para o aperfeiçoamento do Programa.

\section{COORDENAÇÃO INTERGOVERNAMENTAL EM SISTEMAS FEDERATIVOS}

Segundo Abrucio (2005), a coordenação intergovernamental é um vetor analítico ainda pouco explorado nos estudos sobre o federalismo brasileiro. Para o autor, ela se identifica com as "formas de integração, compartilhamento e decisão conjunta presentes nas federações" (ABRUCIO, 2005, p. 41). Falar de coordenação de políticas públicas em sistemas federativos implica especificar o arranjo institucional no qual esta se insere, de modo a compreender a dinâmica das relações entre os atores responsáveis pela sua implementação.

Entre outros fatores, a coordenação das políticas sociais está condicionada pelo tipo de federalismo e respectivo padrão de relações intergovernamentais adotado. Para Souza (2008), análises baseadas em tais categorias podem ser dificultadas por imprecisões conceituais, razão pela qual é importante fazer alguns esclarecimentos preliminares.

Abrucio (2005) explica que toda federação deriva de uma situação federalista, caracterizada pela existência de heterogeneidades de cunho territorial, étnico, linguístico, socioeconômico, cultural e político que dividem uma determinada nação. Outra característica 
apontada pelo autor seria a existência de um discurso de unidade na diversidade, resguardando a autonomia local, mas procurando formas de manter a integridade territorial num país marcado por heterogeneidades.

Para Elazar (1987), o federalismo pode ser referido como um arranjo onde diversas unidades de governo se unem mantendo regras próprias com regras compartilhadas. Já as relações intergovernamentais teriam a ver com os caminhos particulares e meios de operacionalizar um regime político, os quais envolvem extensivas e continuadas relações entre os governos federal, estaduais e municipais, ou qualquer combinação possível. Segundo o autor, estas seriam um conceito subsidiário ao de federalismo, um termo técnico de grande uso para explorar os processos em regimes, particularmente, mas não exclusivamente, federativos.

Wright (1988) avalia que o conceito de relações intergovernamentais não substitui o de federalismo, manifestando sua preferência pelo uso do primeiro, visto que explica a formulação e a implementação das políticas públicas, abordando questões relativas aos conteúdos, processos, estratégias e resultados. Além disso, considera que o conceito de relações intergovernamentais inclui um conjunto de atividades e significados não explícitos nem implícitos no federalismo e abrange um rico conjunto de ações informais e percepções dos agentes públicos, sem limitar-se pelo legalismo que domina o discurso e a prática do federalismo.

Diversos autores ressaltam a importância da negociação na manutenção dos princípios federativos, de modo a minimizar riscos de que um nível de governo se sobreponha a outros (ELAZAR, 1987; SMITH, 1985; WRIGHT, 1988; ABRUCIO, 2005). Wright (1988), especialmente, incorpora essa preocupação no desenvolvimento de um modelo teórico construído com base na problematização entre federalismo e relações intergovernamentais nos EUA, identificando três padrões de relacionamento de autoridade entre níveis de governo.

O modelo de autoridade independente ou dual acentua a separação entre níveis de governo, os quais são apenas tangencialmente ligados. Todos os níveis de governo gozam de total independência e autonomia, com distintas responsabilidades, atribuições e áreas de atuação, de modo que eventuais conflitos de jurisdição são arbitrados pela Suprema Corte. Embora esse modelo tenha vigorado até a década de 1930, nos EUA, hoje é considerado obsoleto, tendo em vista o aumento da complexidade das relações entre as unidades de governo trazida pela sociedade industrial moderna.
O modelo de autoridade inclusiva ou centralizada implica dependência e submissão dos níveis estadual e local de governo ao federal, de modo que os primeiros atuam como meros agentes administrativos do segundo. Duas estratégias seriam possíveis caso o governo federal quisesse expandir sua proporção de poder: reduzir os poderes dos estados e dos governos locais, ou de ambos (jogo de soma-zero, onde o aumento do poder de um implica a respectiva perda do poder dos outros); ou, ainda, aumentar o poder do governo nacional, ampliando ou não poderes dos governos estaduais e/ou locais. Embora esse modelo caracterize algumas situações do federalismo americano, o autor afirma que nunca foi predominante.

Já o modelo de autoridade interdependente (sobreposta), que melhor caracteriza o federalismo dos EUA, pressupõe que determinadas políticas envolvam os três níveis simultaneamente. Ao mesmo tempo, as áreas de atuação autônoma e discricionária de cada um são bastante reduzidas e o poder de dominação de um sobre o outro, limitado. O padrão de relação intergovernamental seria, portanto, o da negociação, o qual, segundo o autor, é o que mais caracteriza o federalismo norte-americano.

Wright (1988) ressalta que, como quaisquer modelos simplificados, tais padronizações estão longe de explicar a complexidade da realidade e seus diversos aspectos, mas permitem formulação de hipóteses por concentrar características essenciais de possíveis arranjos de relações intergovernamentais e estratégias de coordenação federativa. Pretende-se utilizá-los no sentido de problematizar a ambiguidade das tendências centralizadoras e descentralizadoras que, simultaneamente, marcaram o contexto político-institucional da formulação e disseminação dos programas de transferência condicionada de renda no país, de modo a identificar os desafios de coordenação intergovernamental do PBF.

\section{FEDERALISMO BRASILEIRO E IMPLICAÇÕES NO DESENVOLVIMENTO DOS PROGRAMAS DE TRANSFERÊNCIA DE RENDA}

A gênese do federalismo brasileiro difere do federalismo americano, cujo modelo constitui referência clássica na literatura sobre o tema, visto que nossa 
formação resultou de um processo de descentralização de um estado unitário, e não da união de estados independentes, como aquele país.

Nossa opção pelo federalismo instaurou-se com a Constituição de 1891. Passamos de um Império unitário e centralizado para uma Primeira República federativa e descentralizada, todavia com uma distribuição de poder regional extremamente desigual, quando, basicamente, São Paulo e Minas Gerais definiam os rumos do país. Nesse período, prevaleceu um modelo de autoridade independente, nos termos de Wright (1988), no qual os estados gozavam de grande autonomia. Os entes federativos só passaram a ter maior interação para a produção de bens e serviços coletivos a partir da década de 1930.

Para Almeida (2001), o grau e a forma de participação das esferas de governo na produção de políticas públicas no Brasil dependeram do caráter mais ou menos centralizado do arranjo federativo prevalecente. Historicamente, períodos de centralização coincidiram com o predomínio de regimes autoritários, enquanto a descentralização ocorreu com a vigência da ordem democrática.

Draibe (1994) identifica as raízes da centralização do nosso sistema de proteção social tendo em vista que seus impulsos iniciais e de consolidação se deram, sobretudo, durante períodos não democráticos, principalmente durante o Estado Novo (1930/1940) e no governo militar (1960/1970). Nesses períodos, as relações intergovernamentais eram, na prática, muito mais próximas às formas que caracterizam estados unitários do que federações, sendo fortemente hierarquizadas, nos moldes do modelo de autoridade inclusiva proposto por Wright (1988).

O processo de redemocratização da década de 1980 pleiteou um novo modelo federativo, descentralizado, tendo em vista a demanda pela maior participação popular e eficiência das políticas públicas. Junto às diversas novidades contempladas pela CF de 1988 - como a ampliação dos direitos sociais verificou-se forte descentralização de recursos, especialmente para os municípios - alçados à categoria de entes federativos juntos aos estados e à União - por meio do aumento nas transferências constitucionais e na autonomia da arrecadação tributária. Esse movimento veio acompanhado do respectivo aumento de responsabilidades relativas à implementação de políticas sociais. Identifica-se também, na CF, a adoção de competências comuns entre os três níveis de governo, no sentido do federalismo cooperativo, o que, por sua vez, atribui um alto nível de interdependência na gestão das políticas sociais, conferindo maior importância a mecanismos de coordenação intergovernamental que potencializem essa ação conjunta.

Ainda que esse novo federalismo tenha permitido várias conquistas ao país - como o surgimento de formas inovadoras de gestão local, a exemplo dos programas de renda mínima em Campinas e no Distrito Federal, em 1995 - o processo de descentralização resultou inicialmente em uma postura defensiva da União, tendo em vista a perda de recursos tributários e a responsabilidade pela estabilidade econômica. Desde o final da década de 1980, e até meados da década seguinte, a crise inflacionária havia tornado instável o repasse de recursos, dificultando o exercício das novas atribuições dos governos locais (ABRUCIO, 2005). O autor ressalta ainda que, nesse período, se conformou o que denominou "federalismo compartimentalizado", na medida em que a União se desincumbiu do seu papel coordenador e cada nível de governo buscou atuar de maneira independente, dada a inexistência de incentivos à atuação conjunta e o estabelecimento de um "jogo de empurra" entre as esferas de governo.

A partir de 1994, com o advento do Plano Real, ocorreram novas transformações no federalismo brasileiro, sobretudo nas áreas fiscal e financeira, com ajustes que buscaram minimizar os efeitos perversos da descentralização desordenada ocorrida até então. Uma mudança significativa foi a introdução da vinculação de gastos dos três níveis de governo nas políticas de educação e saúde, que passaram por um processo de descentralização coordenada, sobretudo na segunda metade da década de 1990, o qual ampliou oportunidades de negociação intergovernamental, respondendo à demanda por maior uniformidade e regularidade no padrão de oferta dessas políticas pelo país.

Sob o aspecto financeiro, Abrucio (2005) afirma que, embora os arranjos intergovernamentais ainda fossem bastante descoordenados, em meados da década de 1990, promoveu-se o fortalecimento do governo federal via medidas tributárias centralizadoras que resultaram no crescimento significativo dos recursos à sua disposição. Entre elas, destacam-se a aprovação de emendas constitucionais que introduziram a desvinculação dos gastos/transferências da União e o aumento das contribuições sociais.

Arretche (2002) avalia que, com essa estratégia, a União garantiu para si recursos voltados para a área social, cujo repasse para as demais esferas de governo supõe transferências sem regras de partilha 
preestabelecidas. Além de recuperar parte das receitas perdidas na partilha fiscal promovida pela $\mathrm{CF}$, a União gradualmente estabeleceu seu papel coordenador no processo de descentralização das políticas sociais, favorecendo a cooperação de estados e municípios com os seus objetivos de reforma.

Em meados da década de 1990, as iniciativas voltadas ao combate da pobreza ainda não tinham iniciado um processo mais consistente de descentralização. A assistência social, inclusive, não tinha avançado muito na implementação das diretrizes da Lei Orgânica de Assistência Social (LOAS). Dessa forma, a União reconheceu a iniciativa meritória das demais esferas de governo na implementação de programas de transferência condicionada de renda e, graças à maior disponibilidade de recursos, viabilizada, inclusive, pela aprovação do Fundo Constitucional de Combate à Pobreza, em 2000, passou a adotá-los em nível nacional. Segundo diversos estudos, essa não foi uma tendência exclusiva do Brasil, tendo se disseminado pela América Latina (DRAIBE, 2009; NASCIMENTO e REIS, 2009).

A União assumiu, então, forte protagonismo na definição dessa agenda e das atribuições dos demais entes federativos na gestão desses programas. Portanto, o contexto de surgimento e expansão dos programas de transferência condicionada de renda é paradoxal. Caracterizou-se por tendências descentralizantes, tendo em vista terem resultado dos processos de inovação fruto do fortalecimento dos governos locais para a implementação das políticas sociais; e centralizantes, dada a maior disponibilidade de recursos para a União.

Almeida (2005) avalia que a implementação desses programas pelo governo federal implicou uma ruptura com o modelo constitucional do federalismo cooperativo para a área social, significando uma volta clara às formas centralizadas de prestação de benefícios sociais. A autora pondera, todavia, que essa tendência não seria suficiente para se afirmar que estaria em curso um processo de "recentralização". Destaca que "a tensão entre impulsos centralizadores e descentralizantes é constitutiva e sempre presente nas relações intergovernamentais na Federação Brasileira e produz diferentes resultados de acordo com a questão de política pública em pauta" (ALMEIDA, 2005, p. 39). A autora pondera que, mesmo nas configurações das políticas de saúde e educação, caracterizadas por um modelo de federalismo predominantemente cooperativo, em que os demais entes federativos mantêm certa autonomia decisória e capacidade de financiamento, seria possível encontrar traços centralizadores característicos dos momentos de expansão da política social no Brasil no século XX.

Afonso (2006) e Abrucio (2005) também apontam traços de centralização na implementação dos programas federais de transferência condicionada de renda. Todavia, avaliamos que não é possível afirmar que esses programas levaram, necessariamente, a uma relação estritamente hierarquizada. É preciso contextualizar que tais análises foram realizadas com base nas primeiras experiências de programas federais dessa natureza e avaliaram os programas como um todo. Já as análises sobre o PBF focaram sobretudo seu momento de expansão inicial, entre 2003 e 2006, quando foi implementada sua dimensão da transferência de renda.

É importante que essa especificidade de tais análises seja levada em conta, de modo a atualizar e qualificar a discussão sobre a centralização dos programas de transferência condicionada de renda em função do desenvolvimento posterior das dimensões mais intersetoriais do PBF.

A noção de intersetorialidade remete à integração de diversos setores com vistas à solução de problemas sociais (GRAU, 2005). Segundo Moreno (2007), a natureza transversal dos grandes temas sociais, como a pobreza, tem demandado respostas nos níveis intra e intergovernamental. No primeiro caso, elas concretizam-se por meio de políticas baseadas na conjunção de esforços, conhecimentos e recursos de diversos órgãos de um mesmo nível de governo. O segundo caso implica a coordenação entre instituições de governos distintos, de igual ou diferente nível. A intersetorialidade e a gestão intergovernamental são, portanto, modalidades de respostas cada vez mais frequentes da administração pública a um entorno complexo, ao mesmo tempo em que são manifestações da complexidade da gestão de políticas sociais em contextos federativos contemporâneos.

A intersetorialidade pode provocar modificações no arranjo institucional das políticas públicas, de modo a afetar o respectivo arranjo federativo de implementação, além de demandar maior capacidade de coordenação. Avaliamos que essa situação aplica-se ao PBF, quando comparamos o padrão de relações intergovernamentais adotado para implementação da transferência de renda (hierarquizado) com o padrão adotado nas suas dimensões intersetoriais (mais negociado). 


\section{PROCEDIMENTOS METODOLÓGICOS}

Esta pesquisa enfoca a interação contextual entre atores, políticas públicas e instituições, partindo do pressuposto de que, embora não sejam os únicos fatores decisivos, as instituições afetam o comportamento dos atores e resultados das políticas. Tal dimensão pode ser apreendida pela análise sobre como os atores mobilizam as instituições em torno de uma política pública em cada contexto histórico. Sob o paradigma do neoinstitucionalismo histórico, discutimos como o federalismo se organiza e se relaciona com as políticas públicas, com base no estudo de caso do PBF.

A presente análise é de natureza qualitativa, tendo como ponto de partida uma revisão bibliográfica sobre o tema do federalismo, relações intergovernamentais e políticas públicas. Por integrar pesquisa de doutorado em andamento, não se baseia em entrevistas, que ainda serão realizadas. Dessa forma, as principais fontes documentais relativas ao PBF que contribuíram para a constituição das informações apresentadas são: regulamentos (leis, decretos, portarias); fontes jornalísticas; pesquisas e documentos técnicos. Dado que as autoras atuaram como servidoras federais na gestão do PBF, no período analisado, a técnica da observação-participante também constitui fonte importante das constatações discutidas, o que explica, inclusive, o uso de informações sobre o Programa ainda não divulgadas em documentos oficiais.

O processo de análise a que foram submetidos os referidos documentos, que permitiu chegar-se às conclusões/afirmações apresentadas, orientou-se pelo modelo teórico de Wright (1988) sobre possíveis padrões de relacionamento de autoridade entre níveis de governo, que podem variar segundo o grau de interdependência, independência ou subordinação entre os entes federativos para implementação de uma determinada política pública.

\section{MODELO DE GESTÃO DO PROGRAMA BOLSA FAMILIA}

O PBF é fruto da unificação das ações de transferência de renda do governo federal em 2003, especialmente as dos Programas Bolsa Escola, Bolsa Alimentação, Auxílio-Gás e do Cartão Alimentação, além do Cadastro Único. Seu modelo de gestão conjuga esforços dos três níveis de governo por meio da criação de uma rede intergovernamental responsável pela sua implementação, viabilizando uma estrutura de coordenação articulada com diferentes políticas sociais, de modo a respeitar a autonomia dos entes federados e a interdependência entre eles.

O Programa prioriza famílias com renda mensal per capita de até $\mathrm{R} \$ 140,00$ para o recebimento da transferência monetária, por meio da sua inclusão na base de dados do Cadastro Único. Conforme a composição familiar e respectiva renda per capita, os benefícios podem variar de $\mathrm{R} \$ 32,00$ a R\$242,00. Atualmente, 50,9\% dos beneficiários residem no nordeste, 24,7\%, no sudeste, 5,8\%, no centro-oeste, $8 \%$, no sul e $10,6 \%$, no norte do país.

As condicionalidades do PBF são definidas como compromissos entre o poder público e as famílias beneficiárias para reforçar o acesso aos direitos sociais básicos. Esses compromissos consistem na manutenção de crianças e adolescentes na escola e no acompanhamento das gestantes (pré-natal), nutrizes (puerpério) e crianças (desenvolvimento/crescimento). Todas as famílias beneficiárias devem ser acompanhadas pelas áreas de saúde, educação e assistência social no âmbito das condicionalidades do Programa, em uma perspectiva de reforçar o direito de acesso a essas políticas universais. Seu monitoramento permite identificar as famílias em situação de maior vulnerabilidade.

O Programa articula, ainda, programas complementares, entendidos como ações que permitem às famílias o desenvolvimento de capacidades geradoras de renda, ainda que sem assegurar sua inserção no mercado formal de trabalho, possuindo papel fundamental para a efetiva superação da pobreza. Nessa dimensão do PBF, todos os níveis de governo assumem o compromisso pela priorização e convergência desse tipo de programa para as famílias beneficiárias.

A gestão do PBF vem sendo construída com base em um elevado grau de interface entre União e municípios. Enquanto a União financia e regulamenta o Programa, grande parte da execução está localizada no nível municipal. As famílias beneficiárias estão em todos os 5.565 municípios e no Distrito Federal, devendo ser atendidas e acompanhadas pelos órgãos locais. O cadastramento e a gestão de benefícios, assim como a prestação dos serviços básicos de saúde, educação e assistência social e articulação de programas complementares, ocorrem nos municípios, com base na oferta do poder local.

A interface com os governos estaduais é mais restrita. Os estados participam da gestão do PBF com a função de apoiar os municípios, principalmente os 
menores e menos estruturados, com suporte tecnológico e capacitação. Embora não atuem diretamente na execução do Programa, a vocação dos governos estaduais para mobilização dos municípios que estão no seu território, bem como para o monitoramento das ações que são realizadas, tem colocado esse nível de governo como um ator de grande relevância para o PBF, na medida em que apoia o trabalho de coordenação a cargo da União.

\section{Estratégias de coordenação intersetorial}

A concepção do Bolsa Família como uma política de combate à pobreza torna-o inequivocamente intersetorial, sobretudo na gestão de condicionalidades e na oferta de programas complementares. As redes criadas para implementação dessas dimensões vêm sendo utilizadas de maneira diferenciada na condução das negociações com os entes federados. Entender essas diferenças é importante, tendo em vista que os padrões adotados na relação intersetorial entre os Ministérios responsáveis pela implementação de ações do PBF no nível federal orientam as relações internas nos outros níveis de governo.

Nas condicionalidades, evidenciam-se interfaces entre o Ministério do Desenvolvimento Social (MDS), Saúde (MS) e Educação (MEC), os quais são corresponsáveis por essa dimensão do PBF e precisam sensibilizar, pactuar e mobilizar seus sistemas de políticas públicas para tanto. Isso vem reforçando o vínculo entre essas políticas setoriais e o público mais pobre, alvo de possíveis dificuldades para acessar tais serviços. O que permeia essa concepção são a construção e a valorização do princípio da equidade em políticas públicas de caráter universal. O acompanhamento dos beneficiários em descumprimento de condicionalidades pelos serviços socioassistenciais, por sua vez, possibilita um atendimento integral a essas famílias, ao viabilizar a superação de suas vulnerabilidades. A oferta conjugada do benefício financeiro e dos serviços sociais básicos evidencia, portanto, o papel do PBF como política articuladora no âmbito do nosso sistema de proteção social.

Em termos de coordenação, a intersetorialidade na gestão de condicionalidades é facilitada pelo mandato explícito da legislação federal para os Ministérios envolvidos. Avalia-se que o fato de envolver políticas universais estruturadas nacionalmente, que contam com arenas próprias e institucionalizadas de negociação intergovernamental, facilita a promoção da complementaridade entre as ações dessas políticas e do PBF, favorecendo a convergência de interesses e a construção de uma agenda comum. Há, inclusive, certo consenso em torno do princípio de que a transferência de renda potencializa e dá sinergia às ações desenvolvidas pelas áreas de saúde (combate à desnutrição, mortalidade infantil e mortalidade materna; promoção da saúde da mulher), de educação (combate à evasão e ao abandono escolar, maior participação dos pais na vida escolar dos filhos) e de assistência social (redução das vulnerabilidades e fortalecimento de vínculos e promoção social).

Cabe destacar a forte interface entre o PBF e a assistência social. Essa relação é ainda mais imediata do que com a saúde e educação, visto estarem sob o mesmo Ministério, no âmbito federal, e dividirem o lócus institucional de gestão em todos os estados e na maior parte dos municípios. Além disso, o PBF utiliza estruturas do Sistema Único de Assistência Social (SUAS), como a Comissão Intergestora Tripartite (CIT), Comissões Intergestoras Bipartites (CIB), ou espaços como o Colegiado Nacional de Gestores da Assistência Social (Congemas) e o Fórum dos Secretários Estaduais de Assistência Social (Fonseas), para negociar com os demais níveis de governo a regulamentação de novos processos. Outra importante interface refere-se à forma de repasse financeiro para apoio à gestão descentralizada do PBF para estados e municípios, por meio dos respectivos fundos de assistência social.

No caso da oferta dos programas complementares para famílias beneficiárias do PBF, o MDS desenvolve estratégias de articulação com diversos órgãos dos três níveis de governo, para atender necessidades das famílias em áreas como inclusão produtiva, alfabetização e qualificação profissional. Essa articulação leva em conta o perfil das famílias atendidas, suas vulnerabilidades e potencialidades, assim como ações já existentes em face das potencialidades econômicas, culturais e naturais específicas de cada localidade. Entretanto, a despeito da existência de programas complementares em diferentes áreas governamentais, verifica-se que ainda não está clara uma real convergência dessas ações para as famílias beneficiárias do PBF, inclusive no nível federal, carecendo de melhor definição de como e por que ela deva ocorrer.

Dados sobre o atendimento de famílias do PBF nesses programas, após início das articulações nesse sentido, ilustram a sua baixa capacidade em fazer frente à grande demanda materializada pelas famílias do PBF. Em 2008, 268 mil beneficiários do PBF 
foram atendidos pelo Programa Brasil Alfabetizado. Até 2010, apenas 1.491 beneficiários do PBF tinham sido atendidos pelo Programa Nacional de Microcrédito Produtivo Orientado do Ministério do Trabalho. Em 2010, cerca de 256 mil famílias do PBF foram beneficiadas pelos programas de microcrédito Agroamigo (23 mil) e Crediamigo (233 mil) do Banco do Nordeste (BRASIL, 2011). Tais resultados evidenciam a fragmentação desses programas, que operam na casa dos "milhares" de beneficiários, enquanto o PBF opera na casa dos "milhões".

A coordenação intersetorial pode assumir complexidades diferenciadas na articulação de programas complementares, sobretudo quando a transferência de renda não é incorporada como um recurso que pode potencializar outras ações e permitir que seus beneficiários tornem-se alvo prioritário de uma série de ações integradas. Verifica-se um grande desafio no sentido de pautar e priorizar o público atendido pelo PBF de modo a abrir novos espaços de inclusão e ampliar espaços já existentes. Isso não é tarefa fácil, visto que alguns programas não estão acostumados a trabalhar com as famílias mais pobres e têm dificuldade para distinguir os beneficiários do PBF como público prioritário de suas ações. De fato, em 2010, a proporção de beneficiários do PBF atendidos pelo Programa Agroamigo foi de apenas 11,3\%, e do Crediamigo, 34,6\%. Já a média do Brasil Alfabetizado é de apenas $20 \%$ por ano. Em nossa avaliação, trabalhar com essas famílias significa um esforço de comunicação e identificação de necessidades individuais e resgate da autoestima que vão além do que boa parte desses programas tradicionalmente executa.

Verifica-se, ainda, uma limitação evidente no papel do MDS para essa articulação, pois não é um órgão transversal com autoridade sobre os outros ministérios responsáveis pelos programas articulados. Embora seja de grande valia o apoio prestado pela Casa Civil da Presidência da República, isso nem sempre tem sido suficiente, tendo em vista a fragmentação e concorrência de ações nos três níveis de governo.

Esses modelos diferenciados de coordenação intersetorial no acompanhamento das condicionalidades e na articulação de programas complementares possuem rebatimento na coordenação intergovernamental. Nesse sentido, destaca-se a distinção entre políticas federais e nacionais elaborada por Sano (2008), a qual ajuda a entender as interações federativas na gestão de políticas públicas. Para o autor, as políticas nacionais envolvem as três esferas de governo, no que se refere às arenas de decisão; à normatividade legal; às formas de financiamento; aos mecanismos de colaboração e aos instrumentos de definição dos conflitos. Já as políticas federais são aquelas elaboradas pela União, as quais, embora também tenham abrangência em todo o território nacional, resultam exclusivamente de decisões da União. Além disso, sua implementação depende, geralmente, da adesão dos demais níveis de governo, mas sem que tenham poder legítimo de interferir no desenho da política. Essa distinção permite identificar a complexidade da gestão do Bolsa Família como estratégia central de combate à pobreza, pois, apesar de ser uma política federal, com participação de estados e municípios regulada por meio de adesão, atua em articulação com políticas nacionais descentralizadas, estruturadas em sistemas/redes com arenas próprias de negociação intergovernamental.

Avalia-se que a diferença fundamental entre ambos os padrões de coordenação refere-se à abrangência das políticas articuladas. No caso das condicionalidades, as políticas nacionais de saúde, educação e assistência social contam com, pelo menos, alguma estrutura de funcionamento descentralizado. Há, portanto, uma base para a negociação, tanto do ponto de vista de espaços institucionalizados quanto de ações estruturadas e coordenadas nos três níveis de governo. Por outro lado, o amplo espectro que abriga os programas complementares ao PBF faz com que sua articulação obtenha resultados mais frágeis, não só por questões de escala e fragmentação em diversos órgãos mas também pela ausência de instrumentos que priorizem, de fato, as famílias mais pobres.

\section{Relações intergovernamentais}

Fonseca e Viana (2006) contam que o lançamento do PBF, em 2003, foi adiado a pedido do Presidente da República, para que negociações relacionadas com a participação de outros níveis de governo no Programa, notadamente dos estados, pudessem ser encaminhadas. A realidade, porém, é que o PBF foi lançado em outubro daquele ano sem que nenhum instrumento de formalização da participação dos demais entes estivesse suficientemente formatado.

A primeira tentativa de formalizar a participação de estados e municípios deu-se com o estabelecimento de pactuações conduzidas caso a caso, guiadas por dois objetivos centrais: integração do PBF com programas próprios de transferência condicionada de renda e arti- 
culação de programas complementares. Esse processo teve como principal virtude a ausência de um modelo padronizado, sinalizando consistentemente, na visão de Fonseca e Viana (2006), o respeito às especificidades locais e de capacidade de participação do ente federado. Essa iniciativa, junto com o processo de unificação dos programas remanescentes, permitiu ao PBF buscar maior racionalidade e eficiência administrativa, eliminando sobreposição de ações, pulverização de recursos e esforços para o enfrentamento da pobreza.

Mesmo que, eventualmente, à época, a pactuação se mostrasse uma boa opção, por sinalizar uma oportunidade de negociação intergovernamental, os custos foram altos. De fato, diante da abrangência e capilaridade do $\mathrm{PBF}$ - presente em todos os municípios do país - cuja estratégia de implementação orientou-se por meio de metas anuais de atendimento, a pactuação caso a caso não permitiu a articulação na velocidade necessária. O balanço no final de 2004 dá ideia das dificuldades do processo: apenas 13 estados, o Distrito Federal e 14 municípios haviam assinado Termos de Cooperação. Entre essas dificuldades, destacam-se o baixo alcance das metas de inclusão de famílias e diversas interrupções/atrasos no repasse dos recursos por parte dos entes federados para o pagamento conjunto dos benefícios (MESQUITA, 2006; BRASIL, 2007).

Em 2005, um novo processo de formalização da participação de municípios e estados foi estabelecido por meio da Portaria GM/MDS n. 246/2005, na forma da assinatura de Termo de Adesão, o qual representa a concordância formal do ente em participar da gestão do Programa e assumir a responsabilidade por determinadas atividades perante a União, definidas conforme o nível de governo. A partir de então, o governo federal, que até então só se responsabilizava financeiramente pelo pagamento da transferência de renda às famílias, passou também a repassar recursos para apoiar a gestão do PBF nos estados e municípios, remunerando ações voltadas ao Cadastro Único. O objetivo foi incentivar o cadastramento de novas famílias, bem como atualizar as informações já existentes, permitindo a concessão de benefícios de modo mais consistente. Esse modelo de repasse vigorou até 2006, quando foi substituído por um novo instrumento, instituído pela Portaria GM/MDS n. 148/2006, que permite a mensuração da qualidade da gestão municipal por meio do respectivo desempenho no cadastramento e acompanhamento das condicionalidades, denominado Índice de Gestão Descentralizada (IGD). A transferência dos recursos aos municípios é feita desde que alcancem os padrões mínimos de gestão desse indicador.

Se, de um lado, a participação dos municípios está definida desde 2005, com a especificação de suas atribuições no Termo de Adesão, o escopo da atuação dos estados no PBF ainda é um processo em construção, como ocorre em outras políticas públicas. Tal indefinição, na opinião de Afonso (2006), é agravada pelo frequente relacionamento direto da União com municípios. Em que pese a problemática relativa à atribuição dos estados no federalismo brasileiro, o fato é que o PBF só passou a especificar melhor o papel desse nível de governo a partir de 2005, propondo uma adesão pontual ao processo de cadastramento. Já em 2008, foi proposta uma adesão dos estados mais ampla ao PBF e criado o Índice de Gestão Descentralizada Estadual (IGDE), nos moldes do IGD municipal.

É preciso analisar o significado da adesão dos entes federados ao PBF. Em geral, adesões são marcadas pelo pressuposto de que há preponderância de um dos atores envolvidos. O outro apenas adere às condições estabelecidas unilateralmente. Em parte, o modelo de adesão do PBF guarda essa característica, na medida em que o instrumento padronizado não é negociado individualmente nem tem seus termos discutidos como na pactuação. A transferência de renda, incluindo o cadastramento e os benefícios, é a dimensão do Programa que apresenta menos espaço para a negociação. De maneira objetiva, diversas atividades devem ser realizadas para que o pagamento dos benefícios aconteça de modo seguro, bem-focado, no prazo e abrangência determinados. Além do incentivo financeiro à gestão, a União conta com outros mecanismos para que a participação dos demais entes federados aconteça da forma desejada. Entre eles, destaca-se a opinião pública, já que as famílias locais somente terão acesso ao benefício se o município aceitar a adesão e empreender a atualização cadastral nos prazos legais, o que pressiona os dirigentes públicos municipais a aceitar as condições federais.

Tudo isso tem contribuído para um padrão mais hierarquizado de relações intergovernamentais na dimensão da transferência de renda, argumento que pode ser evidenciado pelas dezenas de portarias e instruções operacionais relativas à gestão do PBF, publicadas pelo MDS sem negociação prévia com os entes federados.

Outra evidência refere-se aos novos processos de cadastramento e gestão de benefícios, colocados em curso sem que algum tipo de consulta mais estruturada 
aos municípios ocorresse ou sem que suas respectivas capacidades de gestão fossem suficientemente consideradas. Em algumas ocasiões, o governo federal chegou a estabelecer unilateralmente prazos para o estabelecimento de novos procedimentos que impactavam nos benefícios, colocando as equipes municipais sob estresse para atender a população demandante. Isso é agravado pela relação direta entre o beneficiário e o governo federal, apontada por Afonso (2006) como dificultadora das relações intergovernamentais no PBF. De fato, a forte identificação do Programa com o governo federal, somada aos mecanismos de comunicação direta disponibilizados à população pelo MDS e Caixa, pode fragilizar o papel do gestor municipal. Exemplo disso ocorreu em Curitiba, em 2006, ainda no âmbito da primeira grande campanha publicitária federal convocando as famílias para atualização cadastral. Essa situação causou constrangimento ao município, que não foi suficientemente informado sobre esse procedimento e, consequentemente, não havia se organizado adequadamente para a demanda da população (FURLAN, 2006).

Outra dificuldade refere-se à compreensão dos critérios de concessão do benefício, que estão relacionados não apenas ao cadastramento mas também à disponibilidade de vagas baseadas em estimativas municipais. A concessão é feita de maneira centralizada pelo MDS, com base nos critérios de elegibilidade do Programa. Se, por um lado, essa opção garante impessoalidade na escolha dos beneficiários, blindando o Programa contra um eventual clientelismo político local, pode gerar alguma frustração no município onde a realidade das famílias é vivenciada, suscitando o questionamento sobre a seleção. Como o principal critério para inclusão é a renda per capita, famílias mais vulneráveis segundo outros critérios podem não conseguir o benefício por conta da saturação das metas municipais, e não há muita coisa que o gestor municipal possa fazer a respeito.

Esse diagnóstico corrobora, portanto, a avaliação de Almeida (2005), Abrucio (2005) e Afonso (2006) sobre a centralização do $\mathrm{PBF}$, ao menos no que se refere à dimensão da transferência de renda. Todavia, considera-se que esse caminho centralizado trouxe resultados positivos. Um dos mais importantes, decorrente da rápida nacionalização do Programa, refere-se ao impacto socioeconômico. Estudos indicam que o PBF contribuiu significativamente para a redução da desigualdade social (BRASIL, 2006; SOARES e outros, 2006). Quanto à redução da desigualdade regional, destaca-se o aquecimento da economia local dos municípios mais pobres, decorrente das transferências às famílias, que, por possuírem maior proporção de beneficiários do $\mathrm{PBF}$, constituem os territórios que, proporcionalmente, recebem mais recursos do Programa (MARQUES, 2005). Dados de 2007 indicam que, naquele ano, somente os recursos do PBF representaram 36\% do total de transferências constitucionais para o Nordeste, enquanto esse percentual foi de apenas 17\% para o Sudeste - só para ficar com duas regiões extremas em termos de pobreza e desigualdade (BRASIL, 2008).

Por outro lado, o modelo hierarquizado de relações intergovernamentais não tem prevalecido no âmbito das condicionalidades. Universais por concepção da CF, as políticas de saúde, educação e assistência social possuem dinâmicas próprias de negociação intergovernamental, de modo que o PBF precisa respeitar as sistemáticas estabelecidas em cada área e adequar-se para que os resultados sejam alcançados. Evidência disso é a regulamentação do processo de acompanhamento familiar dos beneficiários em situação de vulnerabilidade em conjunto com a assistência social. Como resultado, o "Protocolo de Gestão para a Integração de Serviços e Benefícios" estabeleceu prioridade às famílias beneficiárias da transferência de renda no acesso aos serviços socioassistenciais. Esse instrumento foi construído em conjunto, apresentado à CIT/SUAS, levado a discussão nas CIB e, por fim, aprovado, com a incorporação de diversas contribuições de gestores estaduais e municipais.

Na dimensão das condicionalidades, há uma crescente busca pela maior integração entre as políticas nos três níveis de governo, a qual se deve à premissa de que a atuação intersetorial dará conta de uma abordagem integral da situação de vulnerabilidade em que vivem as famílias beneficiárias. Nesse sentido, destaca-se a criação do "Fórum Intersetorial e Intergovernamental de Condicionalidades do PBF", por meio da Portaria Interministerial MDS/MEC/MS n. 2/2009, formado por representantes do MDS, do MEC, do MS e das entidades de representação de estados e municípios nas três áreas. Tal espaço, voltado para a negociação e o estabelecimento de consensos entre os diversos atores envolvidos, não propõe substituir as estruturas de pactuação de cada política envolvida, mas busca primordialmente aperfeiçoar o papel das condicionalidades, negociar e articular a participação dos demais níveis de governo e a responsabilização política dos atores.

Já no âmbito dos programas complementares, as negociações para a sua oferta não apresentam um modelo predefinido, dependendo, em grande medida, dos 
atores federais responsáveis pela implementação de cada política. Exemplo disso ocorreu com o Planseq/ Próximo Passo, programa de qualificação profissional do Ministério do Trabalho, cuja articulação com o PBF deu-se sob o protagonismo do governo federal em praticamente todas as etapas de implementação, sem uma atuação articulada dos demais entes federados, o que refletiu, em certa medida, a descoordenação da política de emprego, com sobreposições e vácuos de atuação dos entes federativos. No caso específico do Planseq da construção civil, as negociações com estados e municípios limitaram-se à área da assistência social, a qual, junto com os gestores do PBF, via com algum ceticismo a execução de uma ação sem que alguma articulação local fosse realizada. Na avaliação do MDS, nos locais onde os estados e municípios se articularam em torno do Planseq/Próximo Passo, os resultados foram melhores, evidenciando a negociação federativa como um dos principais desafios dessa iniciativa (BRASIL, 2010b).

Diante disso, e dada a perspectiva de aperfeiçoamento do escopo de atribuições dos estados na gestão do PBF, assim como sua natural vocação para coordenação do desenvolvimento regional por meio da identificação das demandas e recursos disponíveis no território, reforçamos a percepção de Mesquita (2006) de que esse tema seria uma oportunidade de atuação mais estratégica desses entes, aproximando-os do centro das decisões do Programa.

\section{DESAFIOS PARA A COORDENAÇÃO INTERGOVERNAMENTAL DO PROGRAMA BOLSA FAMÍLIA}

O presente trabalho buscou evidenciar a importância da discussão sobre o peso da questão federativa na gestão das políticas sociais com base na análise do desenho e implementação do PBF, o qual foi criado em 2003 com a meta de atendimento de toda a população-alvo - 11,1 milhões de famílias - em apenas três anos. Avalia-se que o duplo desafio imposto ao Programa - grande cobertura em curto prazo - somado à herança centralizadora do nosso sistema de proteção social, favoreceu sua centralização no momento inicial de sua implementação, na medida em que requereu a consolidação de uma estrutura nacional de identificação das famílias e pagamento dos benefícios, a qual materializou a dimensão da transferência de renda. No entanto, a construção das demais dimensões do Programa, que inerentemente demandam maior articulação intersetorial - acompanhamento de condicionalidades e articulação de programas complementares - vem se assentando em padrões diferenciados de relações intergovernamentais, levando à construção de redes de articulação que, gradativamente, ampliam oportunidades para negociação entre os entes federativos para sua implementação.

Voltando-se para os modelos de relacionamento entre níveis de governo propostos por Wright (1988), verifica-se que a criação do PBF foi possível por conta do aumento de recursos disponíveis para a União e possibilitou a sua estruturação nacional sob um modelo de autoridade inclusiva. Considera-se que, embora a preponderância da União nas relações com os demais níveis de governo tenha suscitado e agravado alguns conflitos federativos, ela revelou-se importante na materialização da dimensão da transferência de renda, de modo a provocar nítida inflexão nos indicadores de pobreza e desigualdade social.

Posteriormente, caminhou-se para um padrão mais negociado com estados e municípios, o qual vem contribuindo para a gestão compartilhada e intersetorial diante das políticas sociais universais, sobretudo no que se refere ao acompanhamento das condicionalidades, cujas políticas articuladas já passaram por processos de descentralização. No que diz respeito à articulação dos programas complementares, verifica-se um padrão ainda desarticulado de relações intergovernamentais, refletindo problemas de escala, imaturidade da coordenação federativa dessas políticas, fragmentação das iniciativas e sua dificuldade em alcançar os segmentos mais pobres da população.

Com base na presente análise, destacam-se duas ordens de desafios que se colocam para a coordenação intergovernamental do PBF. A primeira é relativa ao maior investimento em espaços e oportunidades de negociação nas relações intergovernamentais em todas as suas dimensões, enquanto a segunda relaciona-se com a necessidade de maior coordenação federativa da articulação de programas complementares.

Considera-se que a coordenação intergovernamental demanda discernimento sobre momentos de avançar, induzir e propor, tanto quanto sobre momentos de aguardar, ouvir e rever. Dessa forma, é importante que, a cada nova medida, o governo federal dê tempo aos governos estaduais e municipais para assimilar e, eventualmente, reformular 
suas atribuições em relação a novos processos, assim como negociar eventuais ampliações ou restrições de responsabilidades. Avalia-se que, embora a gestão de conflitos pela via negociada em diversas arenas possa ser mais custosa e demorada, ela é mais interessante ao PBF, pois acelera seu caminho rumo a uma política pública consolidada, conectada aos sistemas estruturantes das políticas universais já organizados com base na lógica da descentralização. Esse aspecto deve ser reforçado especialmente na dimensão da transferência de renda. Isso reduz os riscos de que o Programa seja afetado por descontinuidades administrativas decorrentes de eventuais mudanças de orientação político-ideológica em todas as esferas de governo e reforça seu papel central no âmbito do nosso sistema de proteção social.

Quanto aos desafios relacionados às dificuldades de articulação de programas complementares, a questão intergovernamental demanda a organização de uma estratégia nacional coordenada, como bem avaliou o MDS (BRASIL, 2010b). A fragmentação dessas políticas em diversos órgãos e em todos os níveis de governo limita qualquer base de negociação intergovernamental, pois enfraquece a capacidade de negociação dos atores legitimados em efetivamente direcioná-las para os beneficiários do PBF. Isso é agravado pela ausência de instâncias intergovernamentais de negociação dessas políticas.

Tendo em vista a responsabilidade dos estados na elaboração de políticas de desenvolvimento regional, argumentamos que esta seria uma grande oportunidade para seu maior empenho na gestão do PBF. Avalia-se que, além de preencher um vácuo de coordenação regional na gestão do Programa como um todo, a maior atuação dos estados, sobretudo na coordenação das ações de geração de trabalho e renda, poderia fortalecer o encadeamento produtivo das situações de interdependência entre as esferas de atuação federal e municipal. Seria esse um passo fundamental no sentido de se avançar na conformação do modelo de gestão compartilhada, descentralizada e intersetorial do PBF diante das demais políticas do sistema de proteção social brasileiro.

\section{REFERÊNCIAS}

ABRUCIO, F. L. A coordenação federativa no Brasil: a experiência do período FHC e os desafios do governo Lula. Revista de Sociologia e Política, n. 24, p. 41-67, 2005.
AFONSO, J. R. R. Novos desafios à descentralização fiscal no Brasil: as políticas sociais e as de transferências de renda. In: Seminário Regional de Política Fiscal, 18, 2006, Santiago. Santiago: Cepal/Ilpes, 2006.

ALMEIDA, M. H. T. de. Federalismo democracia e governo no Brasil: ideias, hipóteses e evidências. Revista Brasileira de Informação Bibliográfica (BIB), n. 51, p. 13-34, 2001.

ALMEIDA, M. H. T. de. Recentralizando a federação? Revista de Sociologia e Política, n. 24, p. 29-40, 2005.

ARRETCHE, M. Federalismo e relações intergovernamentais no Brasil: a reforma de programas sociais. Dados, v. 45, n. 3, p. 431-458, 2002.

BRASIL. Sobre a recente queda da desigualdade de renda no Brasil. Nota técnica. Instituto de Pesquisa Econômica e Aplicada (IPEA). 2006.

BRASIL. Diretrizes para a revisão do processo de pactuação do Programa Bolsa Família com Entes Federados. Nota técnica. Secretaria Nacional de Renda de Cidadania, Ministério do Desenvolvimento Social (MDS), Brasília, 2007.

BRASIL. Prestação de Contas Presidencial (PCPR) 2007. Controladoria Geral da União (CGU), Brasília, 2008.

BRASIL. Matriz de informação social. Secretaria de Avaliação e Gestão da Informação, Ministério do Desenvolvimento Social (MDS), Brasília, 2010a. Disponível em: http://aplicacoes.mds. gov.br/sagi/miv/miv.php. Acesso em 30.01.2010.

BRASIL. Oficina de trabalho do Programa Próximo Passo. Relatório final. Secretaria Executiva, Ministério do Desenvolvimento Social (MDS), Brasília, 2010b.

BRASIL. Relato da articulação com os programas de microcrédito Crediamigo e Agroamigo do Banco do Nordeste. Nota técnica. Secretaria Nacional de Renda de Cidadania, Ministério do Desenvolvimento Social (MDS), Brasília, 2011.

BROWN, C; OATES, W. E. Assistance to the poor in a federal system. Journal of Public Economics, v. 32, p. 307330, 1987.

DRAIBE, S. M. As políticas sociais do regime militar brasileiro: 1964-84. In: SOARES, G. A. D; D'ARAÚJO, M. C. (Ed) 21 anos de regime militar: balanços e perspectivas. Rio de Janeiro: Fundação Getulio Vargas, 1994, p. 271-306. 
DRAIBE, S. M. Programas de transferências condicionadas de renda. In: Cardoso, F. H; Alejandro Foxley (Ed) América Latina: desafios da democracia e do desenvolvimento - políticas sociais para além da crise. Rio de Janeiro: Campus, 2009. p. 103-143.

ELAZAR, D. Exploring federalism. Tuscaloosa: University of Alabama Press, 1987.

FONSECA, A; VIANA, A. L. A. Tensões e avanços na descentralização das políticas sociais: o caso do Bolsa Família. In: FLEURY, S. (Org) Democracia, descentralização e desenvolvimento: Brasil e Espanha. Rio de Janeiro: Fundação Getulio Vargas, 2006.

FURLAN, N. Confusão no recadastramento do Bolsa Família. Paraná Online, Curitiba, 2006. Disponível em: http:// www.parana-online.com.br/editoria/cidades/news/16470 2/?noticia $=$ CONFUSAO $+\mathrm{NO}+$ RECADASTRAMENTO $+\mathrm{DO}+$ BOLSA+FAMILIA. Acesso em 24.07.2011.

GRAU. N. C. La intersectorialidad en el gobierno y gestión de la política social Transversalidad y coordinación de las políticas de estado en el federalismo. X Congreso Internacional del CLAD sobre la Reforma del Estado y de la Administración Pública, Santiago, Chile. 2005.

MARQUES, R. M. A importância do Bolsa Família nos municípios brasileiros. Cadernos de Estudos Desenvolvimento Social em Debate, n. 1, Secretaria de Avaliação e Gestão da Informação. Brasília: Ministério do Desenvolvimento Social, 2005.

MESQUITA, C. S. Contradições do processo de implementação de políticas públicas: uma análise do Programa Bolsa Família 2003-2006. Revista do Serviço Público, Brasília, v. 57, n. 4, p. 465-487, 2006.

MORENO, O M. C. Transversalidad y coordinación de las políticas de estado en el federalismo. In: Concurso del CLAD sobre Reforma del Estado y Modernización de la Administración Pública, 20, 2001, Caracas. ¿Cómo enfrentar los desafíos de la transversalidad y de la intersectorialidad en la gestión pública? Caracas: CLAD, 2007.

NASCIMENTO. A. F; Reis. C. N. Os programas de transferência condicionada de renda na América Latina: especificidades de uma realidade que se mantém. Revista Políticas Públicas, São Luís, v. 13, n. 2, p. 183-193, 2009.
PETERSON, P. E. The price of federalism. New York: Brookings Institution Press, 1995.

SANO, H. Articulação horizontal no federalismo brasileiro: os conselhos de secretários estaduais. 2008. 308 f. Tese de Doutorado em Administração Pública e Governo, EAESP/ FGV, São Paulo, 2008.

SOUZA, C. Federalismo: teorias e conceitos revisitados. Revista Brasileira de Informação Bibliográfica (BIB), v. 65, p. 27-48, 2008.

SOARES, F. V; SOARES, S; MEDEIROS, M; OSÓRIO, R. O. Programas de transferência de renda no Brasil: impactos sobre a desigualdade. Texto para discussão, n. 1228, Instituto de Pesquisa Econômica e Aplicada (IPEA), 2006.

SMITH, B. C. Decentralization: the territorial dimension of the state. London: George Allen \& Unwin, 1985.

WRIGHT, D. S. Understanding intergovernmental relations. Belmont: Brooks/Cole, 1988. 